Uswatun Hasanah, dkk. Analisis Perbedaan Klaim INA-CBGs Berdasarkan

\title{
Analisis Perbedaan Klaim INA-CBGs Berdasarkan Kelengkapan Data Rekam Medis Pada Kasus Emergency Sectio Cesaria trimester I tahun 2013 di RSUD KRT Setjonegoro Kabupaten Wonosobo
}

\author{
Uswatun Hasanah $^{1}$, Eni Mahawati ${ }^{2}$, Dyah Ernawati ${ }^{3}$ \\ Staf Rekam Medis RSUD KRT Setjonegoro Kabupaten Wonosobo' ${ }^{1}$, Dosen Fakultas Kesehatan UDI- \\ NUS ${ }^{2}$, Dosen Fakultas Kesehatan UDINUS ${ }^{3}$
}

\begin{abstract}
ABSTRAK
INA-CBGs adalah sistem software yang digunakan dalam pembayaran klaim jamkesmas, dengan skema pembiayaan yang digunakan adalah casemix sehingga yang menjadi perhatian utama adalah bauran kasus, diagnosis utama, dan prosedur utama yang menjadi acuan untuk menghitung biaya pelayanan. Berdasarkan evaluasi pada studi pendahuluan di RSUD KRT Setjonegoro pada bulan Januari 2013 untuk kasus emergency sectio cesaria (sc) terdapat perbedaan jumlah klaim ( $4,08 \%)$ dan severity level $(34,92 \%)$ berdasarkan kelengkapan data rekam medis.

Metode penelitian ini menggunakan pendekatan evaluatif dan analitik dengan jumlah sampel penelitian sebesar 126 dokumen rekam medis. Data primer dikumpulkan dengan menelusuri dan menelaah dokumen rekam medis untuk pasien jamkesmas dengan kasus sc dan melakukan pengamatan menggunakan pedoman pelaksanaan, aplikasi software INA-CBGs, ICD 10 dan ICD 9 CM serta data ketidaklengkapan pencatatan dokumen rekam medis. Berdasarkan hasil penelitian ditemukan $45 \%$ dokumen rekam medis untuk kasus $s c$ tidak lengkap (riwayat penyakit pasien, tanda tangan operator operasi, hasil konsultasi, laporan pemeriksaan penunjang, diagnosa sekunder dan tanda tangan DPJP) di mana hal tersebut berpengaruh terhadap besaran klaim berdasarkan isian resume medis dan didapatkan perbedaab jumlah klaim setelah dilakukan entry data berdasarkan dokumen rekam medis $(6,34 \%$ atau $23.988 .179,00)$ dan perbedaan severity level $(31,75 \%)$ apabila dilakukan evaluasi menggunakan data rekam medis.

Hasil uji statistik untuk beda klaim menggunakan Wilcoxon diketahui adanya perbedaan signifikan antara severity level sebelum dan setelah data rekam medis dilengkapi ( $p$ value 0,000$)$. Terbukti juga adanya perbedaan sigifikan antara jumlah klaim sebelum dan setelah data rekam medis dilengkapi ( $p$ value 0,000$)$. Faktor - faktor yang terbukti secara statistik berhubungan signifikan dengan perbedaan besaran klaim adalah ketelitian koder $(p$ value 0,000$)$ dan kelengkapan diagnosa sekunder ( $p$ value 0,000$)$. Sedangkan faktor lain yang belum terbukti berhubungan secara statistik dengan perbedaan jumlah klaim adalah software INA-CBGs ( $p$ value 0,053 ) dan prosedur entry ( $p$ value 0,053 ).
\end{abstract}

Katakunci:INA-CBGs, jamkesmas, sectiocesaria, rekammedis,DifferencesINA-CBGsclaims basedonthecompleteness of medical records in case of emergency cesarean sectio first trimester of 2013 at RSUD KRT Setjonegoro Wonosobo.

\section{ABSTRACT}

INA-CBGs is a software system that is used in the payment of claims jamkesmas, financing scheme used is casemix so the main concern is the mix of cases, primary diagnosis and principal procedure which is used to calculate the service charge. Evaluation based on a preliminary studi in RSUD KRT. Setjonegoro in January 2013 in the case of emergency cesarean sectio there are differences in the amount of claims (4,08\%) and the severity level $(34,92 \%)$ based on the completeness of medical records.

This research method using analytic and evaluative approach to the total sample of 126 medical records document. Primary data were collected by tracking and reviewing medical records to document patient health card with cesarean section case and make observations using the implementation guidelines (manlak), INA-CBGs software applications, ICD 10 and ICD 9 CM and incompleteness of data recording medical record documents.

Based on the results study found $45 \%$ of medical record documents for the case of incomplete sc (history of the disease the patient, operator signature operations, the results of the consultation, investigation reports, secondary diagnosis and signature DPJP) where it affects the amount of a claim based on medical resume stuffing and obtained different result number $(6,34 \%$ or $23.988 .179,00)$ and severity level $(31,75 \%)$ when evaluated using medical records. 
Statistical test results using wilcoxon test known significant differences between severity levels before and after the medical records completed ( $p$ value 0.000). Significant differences also proved between the amount of claims before and after the medical records completed ( $p$ value 0.000 ). Factors that proved to be significant statistically associated with differences of the amount of claim is the coder accuracy ( $p$ value 0.000 ) and completeness secondary diagnoses ( $p$ value 0.000$)$. While other factors were not enough statistical evidence related to the differences the amount of claims were software INA-CBGs ( $p$ value 0.053 ) and entry procedures ( $p$ value 0.053 ). Suggestions for improvements that PJSN team engage in training on the INA-CBGs software, the doctors and paramedics on the completeness of clinical data as a basis for claims of INA - CBGs pattern, making SPO coder must review the provisions of DRM, especially for cases with different claims are too high and give feedback to the team National Casemix Centre (NCC) on some cases to improve software INA - CBGs .

Keywords : INA-CBGs, jamkesmas, sectio caesarea, medical record

\section{PENDAHULUAN}

Rumah Sakit Umum Daerah (RSUD) KRT. Setjonegoro Kabupaten Wonosobo adalah rumah sakit tipe $\mathrm{C}$ dan telah menjalankan program jamkesmas berdasarkan Permenkes nomor 125/ MENKES/III/2008 sebagai landasan dalam perhitungan biaya klaim pasien jamkesmas yang menyatakan bahwa mulai tanggal 1 Januari 2008 diberlakukan system pembayaran klaim pasien peserta jamkesmas menggunakan paket INA-CBGs. Dalam paket INA-CBGs skema pembiayaan yang digunakan adalah casemix dimana diagnosis utama menjadi acuan untuk menghitung biaya pelayanan..$^{(1)}$ Dalam penentuan tarif klaim jamkesmas didasarkan atas diagnosa akhir dan tindakan/ prosedur medis terhadap pasien yang nantinya oleh petugas rumah sakit dientry dalam software INA-CBGs dan keluar dalam bentuk grouping/ kelompok kasus dan $S L$ nya yang menentukan tarif klaim yang dibayarkan. Oleh karena diagnosa akhir serta komplikasi yang dientry sebagai penentu dari besarnya klaim harus mewakili dari segala biaya yang dikeluarkan rumah sakit dalam menangani pasien sehingga data dalam rekam medis harus benar- benar akurat untuk menghindari ketidaktelitian dalam pencatatan yang mengakibatkan kerugian fatal bagi rumah sakit.

\section{METODE PENELITIAN}

Desain penelitian menggunakan metode pendekatan evaluatif analitik dengan 126 sampel penelitian (total DRM kasus sc pasien jamkesmas semester 1 tahun 2013). Data primer dikumpulkan dengan menelusuri dan menelaah dokumen rekam medis untuk pasien Jamkesmas pada kasus sc dan melakukan pengamatan (observasi) dengan menggunakan data pelaporan Jamkesmas, Buku Pedoman Pelaksanaan Jamkesmas (Manlak), aplikasi software casemix INA-CBGs, buku ICD 10 dan ICD 9 $C M$, dan data ketidaklengkapan pencatatan dokumen rekam medis. Data sekunder dikumpulkan dengan mewawancarai beberapa informan dipilih secara purposive yang dianggap mewakili dan kompeten terhadap bidangnya.

\section{HASIL DAN PEMBAHASAN}

Tabel 3.1 Angka ketidaklengkapan pencatatan catatan medis (KLPCM) kasus SC trimester I tahun 2013

\begin{tabular}{|c|c|c|c|c|c|c|c|}
\hline \multirow{2}{*}{ Jenis formulir } & \multicolumn{2}{|c|}{ Lengkap } & \multicolumn{2}{|c|}{ Tidak lengkap } & \multicolumn{2}{|c|}{ Total } & \multirow{2}{*}{ keterangan } \\
\hline & Jml & $\%$ & $\mathbf{J m l}$ & $\%$ & Jml & $\%$ & \\
\hline Pendaftaran & 0 & 0 & 126 & 100 & 126 & 100 & $\begin{array}{l}\text { Nama keluarga, pendidikan, suku bangsa, } \\
\text { tempat bekerja, nama ayah/ibu, jam keluar } \\
\text { rs, komplikasi, anestesi, tanda tangan } \\
\text { dokter yang merawat }\end{array}$ \\
\hline Riwayat kepenyakitan & 0 & 0 & 126 & 100 & 126 & 100 & Tidak ada formulir \\
\hline Riwayat pemeriksaan fisik & 0 & 0 & 126 & 100 & 126 & 100 & $\mathrm{Rr}, \mathrm{bb}, \mathrm{tb}$ \\
\hline Observasi klinis & 126 & 100 & 0 & 0 & 126 & 100 & \\
\hline Perintah dokter & 126 & 100 & 0 & 0 & 126 & 100 & \\
\hline $\begin{array}{l}\text { Laporan prosedur diagnostik } \\
\text { dan terapeutik }\end{array}$ & 0 & 0 & 126 & 100 & 126 & 100 & $\begin{array}{l}\text { Laporan operasi dan anestesi tidak ada } \\
\text { tanda tangan dokter yg menangani }\end{array}$ \\
\hline
\end{tabular}


Uswatun Hasanah, dkk. Analisis Perbedaan Klaim INA-CBGs Berdasarkan

\begin{tabular}{|c|c|c|c|c|c|c|c|}
\hline Laporan konsultasi & 60 & 48 & 66 & 52 & 126 & 100 & $\begin{array}{l}\text { Laporan konsultasi tidak ditulis di form } \\
\text { dokter }\end{array}$ \\
\hline Resume medis & 0 & 0 & 126 & 100 & 126 & 100 & $\begin{array}{l}\text { Tanda tangan dokter yang menangani, hasil } \\
\text { pemeriksaan penunjang, diagnosa sekunder }\end{array}$ \\
\hline Instruksi untuk pasien & 126 & 100 & 0 & 0 & 126 & 100 & \\
\hline $\begin{array}{l}\text { Izin, otorisasi (pemberian } \\
\text { hak kuasa) dan pernyataan }\end{array}$ & 126 & 100 & 0 & 0 & 126 & 100 & \\
\hline Total & 564 & $45 \%$ & 696 & $55 \%$ & 1260 & $100 \%$ & \\
\hline
\end{tabular}

Berdasarkan tabel 3.1 menunjukkan bahwa angka ketidaklengkapan pencatatan medis masih tinggi sebesar 55\%, dimana untuk informasi medis yang berkesinambungan dibutuhkan kelengkapan pencatatan, semakin lengkap tenaga kesehatan memberikan data tindak lanjut dalam pelayanan kesehatan berarti semakin banyak pemanfaatan kelengkapan informasi oleh tenaga kesehatan, ${ }^{(8)}$ berarti pula kualitas pelayanan kesehatan yang diberikan semakin dapat dibuktikan sesuai dengan standar pelayanan kesehatan terkait. Keterkaitan dengan hasil yang akurat dalam rekam medis seperti diabstraksikan dalam resume medis digunakan sebagai data bagi rumah sakit untuk reimbursment dengan pihak asuransi (jamkesmas) untuk kasus sc terdapat $100 \%$ resume medisnya tidak lengkap.

\section{Grafik 3.1 Besaran klaim jamkesmas kasus sc berdasarkan isian resume medis trimester I tahun} 2013

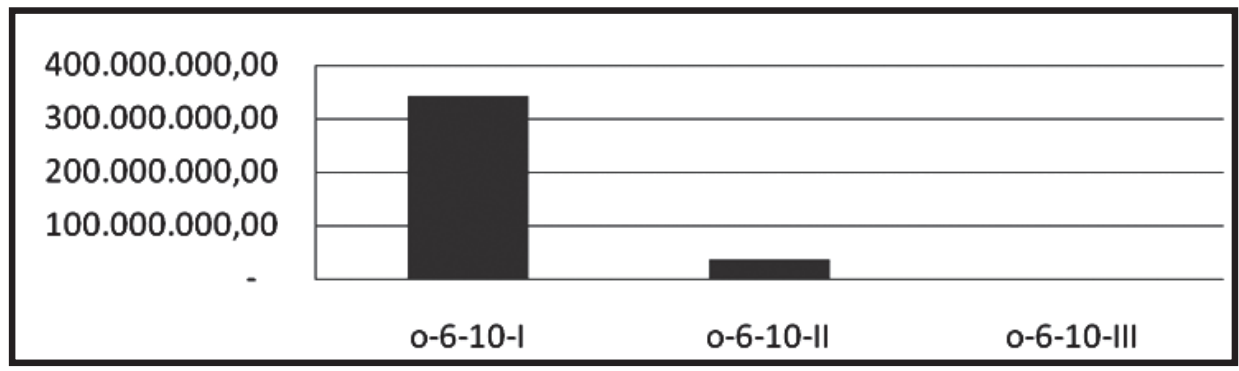

Berdasarkan grafik 3.1 diketahui bahwa terbanyak adalah SL1 sebanyak Rp. 341.888.330,00 atau 90.40\% dari total klaim (Rp. 378.192.939,00).

Tabel 3.2 Besaran klaim berdasarkan data rekam medis kasus sc trimester I tahun 2013

\begin{tabular}{|c|c|c|c|c|c|c|}
\hline Bulan & Tarif $I N A-C B G S$ & Jumlah & $\begin{array}{l}\text { Tarif setelah } \\
\text { dilengkapi }\end{array}$ & $\begin{array}{l}\text { Selisih tarif } I N A- \\
C B G s \text { dg tarif } \\
\text { setelah dilengkapi }\end{array}$ & $\%$ & Keterangan \\
\hline Januari & $122.873 .053,00$ & 41 & $127.882 .007,00$ & $5.008 .954,00$ & $4,08 \%$ & $\begin{array}{l}\text { Naik dari SL1 ke SL2 ada } 12 \\
\text { DRM }\end{array}$ \\
\hline Februari & $117.254 .646,00$ & 39 & $122.687 .876,00$ & $5.433 .230,00$ & $4.63 \%$ & $\begin{array}{l}\text { Naik dari SL1 ke SL3 ada } 1 \text { DRM } \\
\text { Naik dari SL1 ke SL2 ada } 10 \\
\text { DRM }\end{array}$ \\
\hline Maret & $138.065 .240,00$ & 46 & $151.611 .235,00$ & $13.545 .995,00$ & $9.81 \%$ & $\begin{array}{l}\text { Naik dari SL1 ke SL3 ada } 2 \text { DRM } \\
\text { Naik dari SL1 ke SL2 ada } 15 \\
\text { DRM }\end{array}$ \\
\hline \multirow{3}{*}{$\begin{array}{l}\text { Tri } \\
\text { mester ke-1 }\end{array}$} & \multirow{3}{*}{$378.192 .939,00$} & \multirow{3}{*}{126} & \multirow{3}{*}{$402.181 .118,00$} & \multirow{3}{*}{$23.988 .179,00$} & \multirow{3}{*}{$6,34 \%$} & Naik dari SL 1 ke SL3 ada 8 DRM \\
\hline & & & & & & $\begin{array}{l}\text { Naik dari SL1 ke SL2 ada } 37 \\
\text { DRM }\end{array}$ \\
\hline & & & & & & $\begin{array}{l}\text { Naik dari SL1 ke SL3 ada } 11 \\
\text { DRM }\end{array}$ \\
\hline
\end{tabular}

Berdasarkan tabel 3.2 menunjukkan bahwa terdapat perbedaan 6,34\% atau Rp. 23.988.179,00 dari data resume medis apabila dibandingkan dengan data yang telah dilengkapi dari rekam medis. Sedangkan untuk data dalam rekam medisnya terkoreksi SL 40 dokumen rekam medis atau sebesar $32 \%$. 
Grafik 3.2

Rasio klaim jamkesmas dalam rupiah berdasarkan resume medis dan data rekam medis trimester I tahun 2013

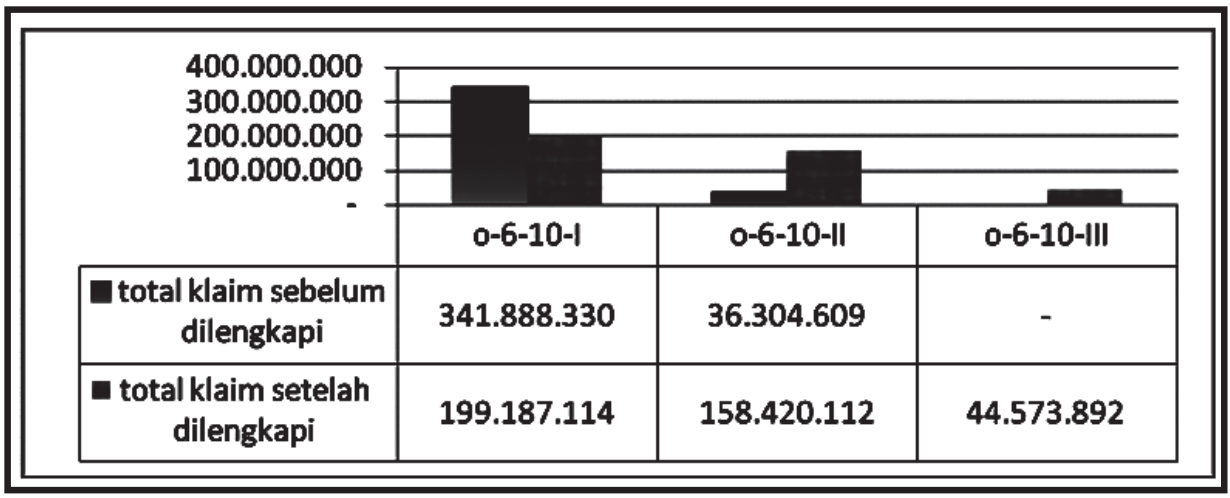

Berdasarkan gambar dalam grafik 3.2 menunjukkan bahwa untuk SL1 terdapat penurunan sebesar Rp. 142.701.216,00 dibandingkan dengan data sebelum dilengkapi. Untuk SL2 terdapat perbedaan sebesar Rp. 122.155.503,00 atau naik 23,02\% sedangkan untuk SL3 terkoreksi sebesar Rp. 44.573.892,00 dari data yang belum dilengkapi.

Faktor- Faktor yang Menimbulkan Perbedaan Besaran Klaim

\section{Naik dari SL1 ke SL2}

Berdasarkan tabel 3.3 menggambarkan bahwa apabila diagnosa primer sc dilengkapi dengan diagnosa sekunder ketuban pecah dini (KPD) lebih dari 24 jam, anemia dengan keterangan setelah perdarahan, dan lahir prematur (kondisi melahirkan sebelum masa melahirkan/ <36 minggu) akan menyebabkan SL naik dari SL1 menjadi SL2.

Tabel 3.3 Kasus sc dengan severity level (SL2) trimester I 2013

\begin{tabular}{|c|c|c|c|c|c|c|}
\hline \multicolumn{2}{|l|}{ Diagnosa utama } & \multicolumn{2}{|l|}{ Diagnosa sekunder } & \multicolumn{2}{|l|}{ Prosedur medis } & \multirow{2}{*}{ Keterangan DRM } \\
\hline Diagnosa & $I C D 10$ & Diagnosa & $I C D 10$ & Prosedur & $I C D 9 C M$ & \\
\hline SC emergency & O82.1 & $K P D>24$ jam & O42.1 & $\begin{array}{l}\text { Low cervical cesarean } \\
\text { section }\end{array}$ & 74.1 & 560153,562956 \\
\hline SC emergency & O82.1 & $\begin{array}{l}\text { Acut post } \\
\text { hemorrhagic } \\
\text { anemia }\end{array}$ & $\begin{array}{l}\text { O99.0 } \\
\text { D62 }\end{array}$ & $\begin{array}{l}\text { Low cervical cesarean } \\
\text { section } \\
\text { Transfusi }\end{array}$ & $\begin{array}{l}74.1 \\
99.04\end{array}$ & $\begin{array}{ll}561045, & 551664, \\
560868, & 560526, \\
551115, & 560360, \\
550732, & 549959, \\
539760, & 562579, \\
551386, & 562516, \\
562319, & 552777, \\
562214, & 561998, \\
561910, & 551728, \\
551918, & 562831, \\
563385, & 563397, \\
563672, & 553273, \\
563457, & 563073, \\
562755, & 564107, \\
551316, & 562620, \\
364613, & 563023, \\
563642, & \end{array}$ \\
\hline SC emergency & O82.1 & $\begin{array}{l}\text { Prematurity } \\
\text { delivery }\end{array}$ & O60 & $\begin{array}{l}\text { Low cervical cesarean } \\
\text { section }\end{array}$ & 74.1 & 560819, 560094, \\
\hline
\end{tabular}


Uswatun Hasanah, dkk. Analisis Perbedaan Klaim INA-CBGs Berdasarkan

\section{Naik dari SL1 ke SL3}

Tabel 3.4 Kasus sc dengan severity level (SL3) trimester I 2013

\begin{tabular}{|c|c|c|c|c|c|c|}
\hline \multicolumn{2}{|c|}{ Diagnosa utama } & \multicolumn{2}{|l|}{ Diagnosa sekunder } & \multicolumn{2}{|l|}{ Prosedur medis } & \multirow[b]{2}{*}{ Keterangan DRM } \\
\hline Diagnosa & $\begin{array}{c}I C D \\
10\end{array}$ & Diagnosa & ICD 10 & Prosedur & $\begin{array}{c}\text { ICD } 9 \\
C M\end{array}$ & \\
\hline SC emergency & O82.1 & $\begin{array}{l}\text { Supervision of other high } \\
\text { risk pregnancies }\end{array}$ & $\mathrm{Z} 35.8$ & $\begin{array}{l}\text { Low cervical cesarean } \\
\text { section } \\
\text { ICU }\end{array}$ & 74.1 & $\begin{array}{l}550624,561700, \\
561630,563084, \\
563582, \\
563691, \\
564093,563709, \\
563145,553283\end{array}$ \\
\hline SC emergency & O82.1 & $\begin{array}{l}\text { ARF } \\
\text { Leukopenia }\end{array}$ & $\begin{array}{l}\text { O90.4 } \\
\text { O99.1 } \\
\text { D72.9 }\end{array}$ & $\begin{array}{l}\text { Low cervical cesarean } \\
\text { section } \\
\text { ICU }\end{array}$ & 74.1 & 563537 \\
\hline
\end{tabular}

Sumber: data primer hasil grouping software INA-CBGs tahun 2013

Berdasarkan tabel 3.4 menunjukkan bahwa dengan diagnosa primer sc apabila dilengkapi dengan diagnosa sekunder resiko tinggi yang memerlukan perawatan intensif di ICU, kasus acut renal failure (ARF/ gagal ginjal sewaktu) dan leukopenia atau gangguan dalam sel darah putih menyebabkan hasil grouping menjadi SL3.

\section{Faktor-Faktor Yang Berhubungan Dengan Per- bedaan besaran klaim Ketelitian koder}

Hasil wawancara mendalam tentang sumber daya manusia untuk penerapan INA-CBGS diketahui bahwa tenaga yang ada belum memadai secara kuantitas dan kualitas. Selain itu ketelitian dan kecermatan petugas koding dalam mengartikan diagnosa dan istilah- istilah medis dokter ke dalam bahasa klasifikasi internasional (ICD 10) yang nantinya menghasilkan kode penyakit dan kode tindakan (ICD 9 CM). Petugas koding juga harus mempunyai kompetensi dalam mereseleksi diagnosa sesuai urutan sebab pokok penyakit dimana hal ini membutuhkan juga pengalaman yang cukup lama. Berdasarkan uji statistik chi square diketahui bahwa ada hubungan antara faktor sumber daya tenaga (ketelitian koder) dan klaim jamkesmas dengan $p$ value sebesar $(0,000)$.

\section{Prosedur entry}

Dalam proses entry ke sistem INA-CBGs didapatkan beberapa kasus dimana apabila dilakukan penambahan diagnosa sekunder yang ditemui dalam berkas rekam medis pasien yang bersangkutan tetapi tidak terekam dalam resume medis mengakibatkan peningkatan SL. Berdasarkan uji chi square diketahui tidak ada hubungan antara prosedur entry dengan klaim INA-CBGs dengan $p$ value sebesar $(0,053)$.

\section{Kelengkapan diagnosa sekunder}

Beberapa kasus ditemukan untuk laporan konsultasi dengan bagian spesialisasi lain juga tidak diabstraksikan dalam resume medis padahal apabila hal tersebut dimasukkan akan meningkatkan SL. Berdasarkan uji chi square diketahui bahwa ada hubungan antara material (kelengkapan diagnosa sekunder) dan klaim INA-CBGs dengan $p$ value sebesar $(0,000)$.

\section{Software INA-CBGS}

Untuk kasus- kasus tertentu logic dalam software versi 3.1 ini juga nantinya perlu dilakukan revisi seperti untuk kasus- kasus dibawah ini:

Tabel 3.5 Logic kasus dalam INA-CBGs yang memerlukan penyempurnaan

\begin{tabular}{|c|c|c|c|c|}
\hline \multicolumn{2}{|c|}{ Diagnosa } & \multicolumn{2}{|r|}{ prosedur } & \multirow{2}{*}{ grouping } \\
\hline primer & Sekunder & primer & sekunder & \\
\hline Sc emergency & Rupture uteri & Lower uterin segment sc & Repair of uterus and supporting structure & $0-6-10-1$ \\
\hline Sc emergency & Atonia uteri & Lower uterin segment sc & Hysterektomy & $0-6-10-1$ \\
\hline Multiple sc emergency & Obstructed labour & Lower uterin segment sc & - & $0-6-10-1$ \\
\hline Sc emergency & Sterilisasi & Lower uterin segment sc & Poomeroy operations & $0-6-10-1$ \\
\hline Sc emergency & Pre eklamsia berat & Lower uterin segment sc & - & $0-6-10-1$ \\
\hline Sc emergency & $\begin{array}{l}\text { Female pelvic peritoneal } \\
\text { adhesions }\end{array}$ & Lower uterin segment sc & Laparascopy lysis of peritoneal adhesions & o-6-10-1 \\
\hline Sc emergency & Eklampsia in labour & Lower uterin segment sc & - & $0-6-10-1$ \\
\hline
\end{tabular}

Sumber: data primer simulasi grouping menggunakan software INA-CBGs 3.1 
Berdasarkan uji chi square diketahui untuk software INA-CBGs yang sesuai logic akan menyebabkan severity level yang berbeda $(63,4 \%)$ dibandingkan dengan yang tidak sesuai logic.

\section{Uji statistik beda klaim}

Berdasarkan uji statistik Wilcoxon yang telah dilakukan diketahui bahwa ada beda jumlah SL dan jumlah klaim sebelum dilengkapi dan setelah dilengkapi dengan $p$ value $(0,000)$. Berdasarkan hasil penelitian terhadap kelengkapan penulisan pencatatan rekam medis selama trimester I tahun 2013 untuk kasus sc ditemukan sejumlah 45\% dari 126 dokumen rekam medis tidak lengkap, dimana data yang tidak lengkap paling banyak terdapat dalam lembar laporan operasi dan anestesi (100\%) dan ringkasan masuk dan keluar (100\%). Sedangkan penulisan yang tidak lengkap pada laporan operasi dan ringkasan keluar yaitu belum adanya tanda tangan dokter yang menangani (DPJP), selain itu juga untuk form dalam resume medis ditemukan beberapa isian yang kurang lengkap terutama untuk kondisi lain/ diagnosa sekunder dan hasil- hasil pemeriksaan penunjang, kurang spesifiknya penulisan apabila dibandingkan dalam rekam medis pasien. Semua pencatatan harus ditandatangani oleh dokter/ tenaga kesehatan lainnya sesuai dengan kewenangannya dan ditulis nama terang serta diberi tanggal, pencatatan yang dibuat oleh mahasiswa kedokteran dan mahasiswa lainnya ditandatangani dan menjadi tanggung jawab dokter yang merawat atau oleh dokter pembimbing, catatan yang dibuat oleh residen harus diketahui oleh dokter pembimbingnya. ${ }^{(2)}$ Dalam pelaksanaan proses grouping di RSUD KRT Setjonegoro Wonosobo data didapatkan dari dokumen rekam medis yang telah dituliskan resumenya oleh ruangan rawat inap (bangsal obsgyn) dan koder yang merupakan bagian dari tim PJSN menuliskan kode ICD 10 dan ICD $9 C M$. Untuk beberapa kasus yang menimbulkan beda terlalu besar antara tarif riil dan tarif INA$C B G s$ maka koder melihat kembali isian dalam data rekam medis pasien. Informasi yang terdapat dalam ringkasan riwayat pulang (resume atau discharge summary) merupakan ringkasan dari seluruh masa perawatan dan pengobatan pasien sebagaimana yang telah diupayakan oleh para tenaga kesehatan dan pihak terkait. Lembar ini harus ditandatangani oleh dokter yang merawat pasien. ${ }^{(3)}$ Sebagaimana diketahui angka ketidaklengkapan pencatatan medis yang masih tinggi (45\%) merupakan suatu tantangan tersendiri yang mendesak untuk diselesaikan karena menimbulkan hambatan bagi koder dalam mengartikan dan membuat kesimpulan dari rangkaian diagnosa yang dituliskan oleh dokter. Dari sampel sejumlah 126 pasien ditemukan ada beberapa diagnosis yang menyebabkan naiknya SL diantaranya yaitu pada kasus sc dengan KPD $>24$ jam hal ini dikarenakan bahwa periode laten merupakan waktu antara ketuban pecah hingga muncul tanda- tanda inpartus. Ada hubungan yang signifikan antara lama periode laten ketuban pecah dini pada kehamilan aterm terhadap nilai $A P G A R$ pada persalinan $(\mathrm{p}<0.001) .{ }^{(4)}$ Pada kasus persalinan sc yang belum masanya atau preterm dapat meningkat menjadi SL2 dikarenakan ibu yang mengalami persalinan preterm dalam usia kehamilan 34-36 minggu lebih beresiko untuk melahirkan bayi dengan resiko asfiksia, berat bayi lahir rendah dan infeksi neonatorum. (5) Anemia dalam kehamilan adalah kondisi ibu dengan kadar hemoglobin dibawah 11 gr\% pada trimester I dan III atau kadar hemoglobin 10,5\% pada trimester II (Depkes RI, 2009). Dalam software INA-CBGs untuk kasus anemia dalam kehamilan sebagai diagnosa sekunder dari sc termasuk SL2 atau dapat memperberat kondisi dari sc-nya. Untuk kasus sc dengan leukopenia dapat naik menjadi SL3 dikarenakan leukopenia sebagai faktor yang berisiko tinggi dalam kehamilan. Leukopenia adalah suatu keadaan berkurangnya jumlah leukosit dalam darah, yaitu kurang dari atau sama dengan 5000/ $\mathrm{mm}$.

Berdasarkan penelitian yang dilakukan terdapat beberapa faktor yang menimbulkan perbedaan antara hasil dari resume medis dan data rekam medis diantaranya adalah sebagai berikut:

\section{Ketelitian koder}

Ketelitian dan kecermatan petugas koding dalam mengartikan diagnosa dan istilah-istilah medis dokter ke dalam bahasa klasifikasi internasional (ICD 10) yang nantinya menghasilkan kode penyakit dan kode tindakan (ICD $9 C M$ ). Petugas koding juga harus mempunyai kompetensi dalam mereseleksi diagnosa sesuai urutan sebab pokok penyakit dimana hal ini membutuhkan juga pengalaman yang cukup lama. Disamping itu belum adanya standar prosedur operasional (SPO) yang mengatur kapan koder harus mereview dokumen rekam medis terutama untuk kasus-kasus dengan kerugian klaim yang cukup tinggi dimana hal ini diperlukan bagi koder sebagai acuan dalam melakukan kegiatan pengkodean.. Berdasarkan uji Chi square yang dilakukan diketahui ada hubungan antara faktor ketelitian koder dan klaim INA-CBGs ( $p$ value 0,000$)$.

\section{Prosedur entry}

Berdasarkan data rekam medis 126 kasus, untuk data sekunder dan hasil- hasil pemeriksaan penunjang 
Uswatun Hasanah, dkk. Analisis Perbedaan Klaim INA-CBGs Berdasarkan

seluruhnya tidak dicantumkan dalam resume medis dimana hal ini mengakibatkan kesulitan bagi koder untuk mencari kode yang pas sehingga kode yang dihasilkan seringkali unspecified padahal apabila ditelaah dalam rekam medis telah tercatat kondisikondisi yang relevan dengan ICD 10. Beberapa kasus ditemukan untuk laporan konsultasi dengan bagian spesialisasi lain juga tidak diabstraksikan dalam resume medis padahal apabila hal tersebut dimasukkan akan meningkatkan klaim.

\section{Software INA-CBGs}

Mesin digunakan untuk memberi kemudahan atau menghasilkan keuntungan yang lebih besar serta menciptakan efisiensi kerja. ${ }^{(6)}$ Untuk saat ini software yang digunakan dalam proses klaim menggunakan INA-CBGs versi 3.1 yang mengalami beberapa penyempurnaan dari versi sebelumnya dimana telah dilakukan update tarif yang berlaku, pembentukan special groups untuk kasus khusus dan pengelompokan tarif yang lebih proporsional. Pada beberapa kasus selama trimester 1 tahun 2013 ditemukan kejanggalan diluar logic alami data klinis dimana untuk kasus- kasus dengan komplikasi dianggap sebagai SL yang sama dengan kasus tanpa komplikasi. Hal ini dapat menjadi masukan bagi pembuat software dalam melakukan penyempurnaan logic INA-CBGs.

\section{Kelengkapan diagnosa sekunder}

Beberapa kasus ditemukan untuk laporan konsultasi dengan bagian spesialisasi lain juga tidak diabstraksikan dalam resume medis padahal hal tersebut akan meningkatkan SL. Berdasarkan uji chi square diketahui ada hubungan antara kelengkapan diagnosa sekunder dan klaim INA-CBGs ( $p$ value 0,000).

\section{SIMPULAN}

Besaran klaim berdasarkan resume medis kasus sc trimester I tahun 2013 Rp. 378.192.939,00.

Besaran klaim berdasarkan data rekam medis kasus sc trimester I tahun 2013 Rp. 402.181.118,00.
Perbedaan klaim berdasarkan isian resume medis dan data rekam medis Rp. 23.988.179 dan terdapat 40 DRM yang terkoreksi dari 126 DRM. Hasil uji Wilcoxon diketahui ada beda jumlah SL dan jumlah klaim sebelum dan setelah data rekam medis dilengkapi ( $p$ value 0,000$)$.

Terdapat hubungan sigifikan secara statistik antara ketelitian koder dan kelengkapan diagnosa sekunder dengan perbedaan klaim INA-CBGs ( $p$ value 0,000 ).

Tidak terdapat hubungan secara statistik antara Software INA-CBGS ( $p$ value 0,053) dan prosedur entry ( $p$ value sebesar 0,053 ) dengan perbedaan klaim INA-CBGs.

\section{DAFTAR PUSTAKA}

Thabrany, Hasbullah. Sistem Pembiayaan dan Pembayaran Pelayanan Kesehatan. Dalam: Gemala R Hatta. Pedoman Manajemen Informasi Kesehatan di Sarana Pelayanan Kesehatan. 2008.

Hatta, Gemala. Analisa Kuantitatif dan Kualitatif dalam Rekam Kesehatan Kertas Maupun Elektronik. Dalam: Gemala R Hatta. Pedoman Manajemen Informasi Kesehatan di Sarana Pelayanan Kesehatan. 2008.

Firmanda, Dody. Mutu Layanan Medis dengan Kepastian Biaya.Http://xa.yimg.com. Diakses tgl 16 Maret 2013.

Shevany, Meisha Amanda. Hubungan Antara Lamanya Periode Laten Ketuban Pecah Dini Pada Kehamilan Aterm Dengan Nilai APGAR Pada Persalinan PerVaginam di RSU Bhakti Yudha Depok. Universitas Pembangunan Nasional Veteran Jakarta. 2011

Kusumawati, Yuli. Faktor-faktor Yang Berpengaruh Terhadap Persalinan Dengan Tindakan. Universitas Diponegoro Semarang. 2006

Azwar, Azrul. Pengantar Administrasi Kesehatan , EdisiKedua.PT.BinaRupaAksara.Jakarta. 1996 